RESEARCH REPORT

\title{
Socioeconomic gradients in the prevalence of cardiovascular disease in Scotland: the roles of composition and context
}

\author{
Alastair H Leyland
}

J Epidemiol Community Health 2005;59:799-803. doi: 10.1136/jech.2005.034017

Correspondence to: Dr A H Leyland, MRC Social and Public Health Sciences Unit, University of Glasgow, 4 Lilybank Gardens, Glasgow G12 8RZ, Scotland; a.leyland@ msoc.mrc.gla.ac.uk

Accepted for publication 18 April 2005

Objective: To investigate whether occupational social class and area deprivation are independently associated with the prevalence of cardiovascular disease (CVD) conditions after adjustment for smoking status.

Design: Stratified multistage random sample analysed using multilevel logistic regression.

Participants: 8804 adults aged 18-74 at time of interview in 1998-1999, clustered in 312 small areas.

The outcome considered was a self report of doctor diagnosis of one of a number of CVD conditions. The survey also provided information concerning the respondent's occupational social class and current smoking status. The Carstairs score (based on the 1991 census) was used to describe small area deprivation.

Main results: The gradient in CVD prevalence across individual social class was attenuated and became insignificant when area deprivation was considered. The aggregation of individual social class and smoking to the area level increased the correlation with disease prevalence at the individual level.

Conclusions: Although there is a relation between socioeconomic status and CVD prevalence in Scotland, the relation is dominated by area deprivation. When externally validated deprivation measures are not available, aggregated individual characteristics may show a contextual (as compared with compositional) relation.

$\mathrm{P}$ eoples' health is patterned by individual socioeconomic circumstances and by those of the area of residence. There remains some debate, however, as to the extent to which the features of the local social and physical environments in themselves have an impact on the health of individual residents ${ }^{1}$ and the extent to which the adverse health outcomes experienced by certain communities merely reflect the concentration of people with adverse socioeconomic characteristics or high levels of risk factors. ${ }^{2}$

Incidence of and mortality from cardiovascular disease (CVD) or coronary heart disease have been shown to be linked to individual social status (as measured by occupational social class, ${ }^{3-6}$ education, ${ }^{4-8}$ employment status,,$^{4-6}$ and income ${ }^{9}$ ) and individual risk factors including smoking. ${ }^{3}{ }^{10}$ Studies that have looked for variation between areas have tended to find it after adjustment for individual socioeconomic status and risk factors; some have ascribed this to area level socioeconomic status (as measured by composite measures of area deprivation, ${ }^{4-68}{ }^{2}$ income, ${ }^{7}$ and social capital ${ }^{71}$ ) while others have just reported the existence of area variation. ${ }^{3}$

Prevalence of the same diseases is also linked to individual socioeconomic status and individual risk factors. ${ }^{12-14}$ These studies again found evidence of geographical variation and those that looked for it found an effect of area socioeconomic status independent of the individual characteristics. ${ }^{12-15}$ Research specifically focusing on the prevalence of cardiovascular risk factors has described geographical variations in blood pressure or hypertension, ${ }^{16-18}$ total serum cholesterol, ${ }^{16}$ alcohol consumption, ${ }^{16}$ body mass index, ${ }^{17}{ }^{19}$ physical activity or sedenterism, ${ }^{17}{ }^{19}$ and smoking. ${ }^{17}{ }^{19}$ Two studies have shown associations at the area level (of neighbourhood deprivation ${ }^{19}$ and income inequality ${ }^{17}$ ) independent of individual socioeconomic status.

This paper examines whether individual social class and area deprivation are independently associated with the

prevalence of CVD conditions-important risk factors both for subsequent mortality and for the use of health services. It has been shown that failure to adjust sufficiently for different measures of socioeconomic position can lead to misleading estimates of an exposure such as smoking. ${ }^{20}$ This study adjusts for smoking status as an important risk factor for CVD to ensure that individual or area socioeconomic differences do not simply reflect differences in smoking. Given that there is a relation between the socioeconomic characteristics of an area and the prevalence of CVD diseases, this paper considers whether area aggregates of individual risk factors for disease- both social risk factors (occupational social class) and behavioural risk factors (current smoking status)-obtained from the study respondents are also related to disease. If so, is this relation additional to the relation at the individual level?

\section{METHODS}

\section{Data}

The data are taken from the 1998 Scottish health survey, ${ }^{21}$ a combined health interview survey and health examination survey conducted between April 1998 and May 1999 and designed to provide "a nationally representative sample of the population of Scotland ... living in private households" ${ }^{22}$ The survey design was a stratified, multistage random sample; interviews were conducted with 9047 people aged between 16 and 74 years from 312 small areas (postcode sectors: approximate population 5000). The sample design ensured that these areas covered the whole country geographically and the sample was stratified by the Carstairs deprivation index. ${ }^{23}$ The sampling unit was the household and one person aged 16-74 was randomly selected

Abbreviations: CVD, cardiovascular disease; DIC, deviance information criterion; MOR, median odds ratio 
from each household to participate in the survey; an interview was obtained from $77 \%$ of the eligible households. Of the 8842 adults aged $18-74$, smoking status was missing for 26 cases $(0.14 \%)$ and the presence of CVD for $12(0.29 \%)$; excluding these cases left 8804 people.

The interviewer asked the respondent whether they had ever been told by the doctor that they had any of the following CVD conditions: heart murmur (excluding while pregnant), diabetes (excluding while pregnant), high blood pressure (excluding while pregnant), angina, heart attack, irregular heart rhythm, other heart condition, or stroke. The dependent variable analysed was the presence of one or more CVD conditions. Social class and smoking were used as individual risk factors; the former was based on the registrar general's classification of occupation, and grouped into high social class (I/II: professional and managerial), intermediate (IIINM and IIIM: skilled workers), and low (IV/V/missing: semiskilled and unskilled manual workers and missing). Smoking was categorised as never smoked, light smokers $(<10$ cigarettes per day), moderate $(10<20)$ and heavy $(20+)$ smokers as well as former smokers. The Carstairs score-an index comprising male unemployment, social class, overcrowding, and lack of car ownership based on the 1991 census - was used as an indicator of material deprivation at the area level. ${ }^{24} 25$

\section{Analysis}

Multilevel modelling using Markov chain Monte Carlo as implemented by the statistical package $\mathrm{MLwiN}^{26}$ took account of the hierarchical data structure imposed through the multistage sample design. ${ }^{27}$ Multilevel logistic regression was used to estimate the associations between the prevalence of CVD conditions and individual social class, area deprivation, and smoking, both independently and simultaneously adjusting for the other risk factors. All models were adjusted for age and sex. Inferences were drawn from chains of length 25000 after a burn-in of 5000; the results presented are the mean and $95 \%$ confidence intervals from the posterior distribution. The significance of risk factors was determined by considering whether the estimated odds ratios differ significantly from 1, and models were compared using the deviance information criterion (DIC). ${ }^{28}$

To assess whether the discriminatory effect of the Carstairs score could be attributed to its being a continuous score (as compared with the three categories used for social class), the Carstairs score was also categorised into three groups-most deprived, mid-deprived, and least deprived—such that about one third of the survey population was in each group. The importance of context was assessed further by aggregating the individual risk factors from the survey data-social class and smoking - to the area level. Area level social class was measured by the difference between the proportion of study respondents in each area in low and high social classes. This measure was chosen in preference to the alternative measure of the proportion of the population in the low social class because it is able to distinguish between areas with the same proportion of the population in the low social class but different proportions in the high (and mid) class. The difference is highly correlated with the proportion in the low social class $(\rho=0.90)$. Area level smoking took individual current smoking levels into account; the score was the average for an area with light smokers coded 1, moderate smokers 2, heavy smokers 3, and never smokers or former smokers coded 0 .

\section{RESULTS}

Table 1 describes the crude and age standardised prevalence of each condition together with the prevalence of any of the conditions for men and women. At least one condition was present in $28 \%$ of men and $27 \%$ of women. The largest single contributing group was high blood pressure, reported by $20 \%$ of men and $19 \%$ of women; excluding this would reduce the prevalence of one or more of the remaining conditions to $16 \%$ and $14 \%$ respectively.

Table 2 shows a simple summary of the covariates among those with and without CVD conditions. Those with one or more conditions are likely to be older (mean age 55 compared with 43 for those with no conditions) and are more likely to be former smokers $(32 \% v 22 \%)$. They are also more likely to come from the most deprived areas, but the other (unadjusted) variables show little signs of any association.

Table 3 presents the results of the modelling as odds ratios together with 95\% confidence intervals. Model A describes the null model (adjusted for just age and sex). The DIC is used to compare models; a lower value suggests a better model (having taken into account the effective number of parameters in the model).$^{28}$ The variance between areas is on the log odds ratio scale and therefore difficult to interpret. Assuming a threshold model, a variance of 0.035 implies an intraclass correlation coefficient of $0.011 .^{29}$ This means that, having adjusted for age and sex, just over $1 \%$ of the differences in the prevalence of CVD conditions is attributable to differences between areas. Alternatively, this variance corresponds to a median odds ratio (MOR) of $1.20 .^{30}$ (The MOR is the median of the odds ratios due to area of residence obtained when comparing two individuals with identical characteristics from two different randomly chosen areas. As an odds ratio the MOR can be compared with any other odds ratios in table 3.) Models B and C add individual social class and smoking status in separate models. There is a

Table 1 Crude and age standardised prevalence of cardiovascular conditions by sex per 10000 population aged 18-64

\begin{tabular}{|c|c|c|c|c|}
\hline \multirow[b]{2}{*}{ Condition } & \multicolumn{2}{|l|}{ Men } & \multicolumn{2}{|c|}{ Women } \\
\hline & Crude & $\begin{array}{l}\text { Age } \\
\text { standardised }\end{array}$ & Crude & $\begin{array}{l}\text { Age } \\
\text { standardised }\end{array}$ \\
\hline Heart murmur & 249 & 240 & 321 & 304 \\
\hline Diabetes & 343 & 304 & 245 & 212 \\
\hline High blood pressure & 1955 & 1790 & 1874 & 1657 \\
\hline Angina & 668 & 551 & 518 & 415 \\
\hline Heart attack & 508 & 420 & 212 & 160 \\
\hline Irregular heart rhythm & 430 & 386 & 471 & 442 \\
\hline Other heart condition & 181 & 164 & 88 & 84 \\
\hline Stroke & 186 & 152 & 154 & 117 \\
\hline Any cardiovascular condition & 2816 & 2563 & 2687 & 2403 \\
\hline $\begin{array}{l}\text { Cardiovascular condition excluding } \\
\text { high blood pressure }\end{array}$ & 1609 & 1413 & 1422 & 1251 \\
\hline
\end{tabular}




\begin{tabular}{|c|c|c|c|c|}
\hline \multirow[b]{2}{*}{ Covariate } & \multicolumn{2}{|c|}{ With CVD condition } & \multicolumn{2}{|c|}{ Without CVD condition } \\
\hline & $\mathrm{N} /$ mean & $\% / S D$ & $\mathrm{~N} /$ mean & $\% /$ SD \\
\hline \multicolumn{5}{|l|}{ Individual level } \\
\hline Age (y) & 55.4 & 13.7 & 42.7 & 14.7 \\
\hline \multicolumn{5}{|l|}{ Sex } \\
\hline Men & 1075 & 44.5 & 2742 & 42.9 \\
\hline Women & 1340 & 55.5 & 3647 & 57.1 \\
\hline \multicolumn{5}{|l|}{ Social class } \\
\hline High & 621 & 25.7 & 1800 & 28.2 \\
\hline Intermediate & 1025 & 42.4 & 2661 & 41.6 \\
\hline Low & 769 & 31.8 & 1928 & 30.2 \\
\hline \multicolumn{5}{|l|}{ Smoking } \\
\hline Never & 872 & 36.1 & 2701 & 42.3 \\
\hline Light & 143 & 5.9 & 434 & 6.8 \\
\hline Moderate & 302 & 12.5 & 968 & 15.2 \\
\hline Heavy & 323 & 13.4 & 910 & 14.2 \\
\hline Former & 775 & 32.1 & 1376 & 21.5 \\
\hline \multicolumn{5}{|l|}{ Area level } \\
\hline Carstairs score & 0.08 & 3.33 & -0.31 & 3.24 \\
\hline \multicolumn{5}{|c|}{ Categorised deprivation } \\
\hline Most deprived & 875 & 36.2 & 2083 & 32.6 \\
\hline Mid deprived & 804 & 33.3 & 2116 & 33.1 \\
\hline Least deprived & 736 & 30.5 & 2190 & 34.3 \\
\hline Area social class & 0.051 & 0.239 & 0.024 & 0.242 \\
\hline Area smoking score & 0.792 & 0.305 & 0.767 & 0.307 \\
\hline
\end{tabular}

slight increase in the odds of CVD conditions across social classes and increased risk among former smokers relative to non-smokers. Model D shows a sharply increasing risk with increasing area deprivation; the DIC suggests substantially improved fit and the Carstairs score seems to explain about half of the variance between areas. The odds ratio of 1.04 (95\% CI 1.02 to 1.06 ) corresponds to a unit increase in the Carstairs score. The interquartile (IQ) range of the Carstairs score for the 312 areas in this sample was 4.11 so the odds associated with living in an area at the 75th centile for deprivation were about $18 \%$ higher than an area at the 25 th centile $(\mathrm{OR}=1.18,95 \% \mathrm{CI} 1.10$ to 1.26$)$.

Model E adjusts for individual social class and smoking status and area deprivation simultaneously. The effect of individual social class is attenuated by the addition of area deprivation, while the odds of CVD conditions remain higher among former smokers compared with never smokers. A comparison of the DIC with model D shows that the addition of individual social class and smoking status does not improve the model containing area deprivation only. When the Carstairs score is categorised in nodel $\mathrm{F}$ a clear gradient is apparent across deprivation tertiles. Although the fit of the model is not as good as for the continuous Carstairs scores (model D), it still represents an improvement over the models containing the individual risk factors (models B and C). Once again the fit of the model containing the categorised deprivation score is not improved by the addition of the individual risk factors (results not shown).

The aggregated social class and smoking scores are strongly positively correlated with each other $(\rho=0.59)$ and with the deprivation score $(\rho=0.69$ and $\rho=0.70$ respectively). Each shows improved fit over the respective individual measure (models $\mathrm{G}$ and $\mathrm{H}$ ). The odds of CVD conditions increase as the difference between the proportion of low and high social class increases and as the area smoking score increases. The odds ratios of 1.59 and 1.46 in models $G$ and $H$ respectively correspond to unit changes in these area variables. The IQ ranges were 0.34 for area social class and 0.45 for area smoking. An increase in the difference between the proportion of people of low and high social class of 34\% would equate to an odds ratio of 1.17 (95\% CI 1.09 to 1.26). An increase in the area smoking score of 0.45 - equivalent to an area having $45 \%$ more light smokers (or 15\% more heavy smokers)—gives an odds ratio of 1.18 (95\% CI 1.09 to 1.28 ). Neither of these aggregated scores has as strong a relation with CVD conditions as the area deprivation score, and the effects of both are attenuated when area deprivation is included (results not shown). For both models $\mathrm{G}$ and $\mathrm{H}$ the addition of the individual risk factors does not improve the model fit (results not shown). Similar results were obtained using the proportion of the population with low social class as the area social class measure (results not shown).

\section{DISCUSSION}

This paper has investigated the prevalence of CVD conditions and not the incidence of CVD (or of the conditions). As such the relation with individual and area risk factors may be complicated. While smoking increases the risk of developing $\mathrm{CVD}^{3}{ }^{10}$ this refers to incidence; the higher rate of prevalent conditions among former smokers seen in this paper is indicative of the tendency to give up smoking after the onset of disease. Similarly, it is possible that disease incidence leads to downward social mobility and that this in part explains the higher prevalence rates among lower social classes. Similar mechanisms may be at work at an area level; those with CVD conditions may move (out of choice or necessity) to more deprived areas, resulting in higher prevalence in these areas.

The limitations of research based on prevalence notwithstanding, there remains a question as to why area measures should be more closely related to CVD conditions than known individual risk factors. It may be a genuine contextual effect, prevalence being higher in more deprived areas because of a combination of higher incidence rates (caused by, for example, environmental influences) and selective migration. Alternatively it is possible that the relative deprivation of the area of residence is a better socioeconomic descriptor of a person than occupational social class. This might explain why the aggregated social class measure is a better predictor of the prevalence of CVD conditions than individual social class; clearly the concentration of manual social classes (and the deficit of professional classes) will be higher in more deprived areas. This results in the prevalence of CVD conditions having 
Table 3 Parameter estimates for models containing individual social class and smoking, area deprivation, and social class and smoking aggregated to the area level $(n=8804)$

\begin{tabular}{|c|c|c|c|c|c|c|c|c|}
\hline \multirow[b]{2}{*}{ Covariate } & \multicolumn{2}{|l|}{ Model A } & \multicolumn{2}{|c|}{ Model B } & \multicolumn{2}{|l|}{ Model C } & \multicolumn{2}{|l|}{ Model D } \\
\hline & OR & $(95 \% \mathrm{Cl})$ & OR & $(95 \% \mathrm{Cl})$ & OR & $(95 \% \mathrm{Cl})$ & OR & $(95 \% \mathrm{Cl})$ \\
\hline \multicolumn{9}{|l|}{$\begin{array}{l}\text { Individual level } \\
\text { Social class (baseline } \\
\text { high) }\end{array}$} \\
\hline Intermediate & & & 1.10 & $(0.97,1.26)$ & & & & \\
\hline Low & & & 1.19 & $(1.03,1.37)$ & & & & \\
\hline \multicolumn{9}{|l|}{$\begin{array}{l}\text { Smoking (baseline } \\
\text { never) }\end{array}$} \\
\hline Light & & & & & 1.17 & $(0.94,1.46)$ & & \\
\hline Moderate & & & & & 0.99 & $(0.84,1.17)$ & & \\
\hline Heavy & & & & & 1.08 & $(0.91,1.27)$ & & \\
\hline Former & & & & & 1.18 & $(1.03,1.34)$ & & \\
\hline Area level & & & & & & & 1.04 & $(1.02,1.06)$ \\
\hline \multicolumn{9}{|l|}{ Carstairs score } \\
\hline \multirow{2}{*}{\multicolumn{9}{|c|}{$\begin{array}{l}\text { Categorised deprivation } \\
\text { (baseline least deprived) }\end{array}$}} \\
\hline \multirow{2}{*}{\multicolumn{9}{|c|}{ Mid-deprived }} \\
\hline & & & & & & & & \\
\hline \multicolumn{9}{|l|}{ Most deprived } \\
\hline \multicolumn{9}{|l|}{ Area social class } \\
\hline \multicolumn{9}{|l|}{ Area smoking score } \\
\hline $\begin{array}{l}\text { Variance between } \\
\text { areas }(95 \% \mathrm{Cl})\end{array}$ & 0.035 & $(0.004,0.079)$ & 0.034 & $(0.006,0.077)$ & 0.041 & $(0.007,0.087)$ & 0.018 & $(0.000,0.054)$ \\
\hline DIC & $\begin{array}{l}9106.4 \\
\text { Model E }\end{array}$ & & $\begin{array}{l}9104.5 \\
\text { Model F }\end{array}$ & & $\begin{array}{l}9105.8 \\
\text { Model G }\end{array}$ & & $\begin{array}{l}9088.1 \\
\text { Model H }\end{array}$ & \\
\hline \multicolumn{9}{|l|}{$\begin{array}{l}\text { Individual level } \\
\text { Social class (baseline } \\
\text { high) }\end{array}$} \\
\hline $\begin{array}{l}\text { Intermediate } \\
\text { Low }\end{array}$ & 1.07 & $(0.94,1.22)$ & & & & & & \\
\hline \multicolumn{9}{|l|}{$\begin{array}{l}\text { Smoking (baseline } \\
\text { never) }\end{array}$} \\
\hline Light & 1.14 & $(0.91,1.42)$ & & & & & & \\
\hline Moderate & 0.93 & $(0.79,1.10)$ & & & & & & \\
\hline Heavy & 1.00 & $(0.84,1.17)$ & & & & & & \\
\hline Former & 1.17 & $(1.04,1.33)$ & & & & & & \\
\hline \multicolumn{9}{|l|}{ Area level } \\
\hline \multirow{2}{*}{\multicolumn{9}{|c|}{$\begin{array}{l}\text { Categorised deprivation } \\
\text { (baseline least deprived) }\end{array}$}} \\
\hline & & & & & & & & \\
\hline Mid-deprived & & & 1.13 & $(0.99,1.30)$ & & & & \\
\hline Most deprived & & & 1.32 & $(1.15,1.51)$ & & & & \\
\hline Area social class & & & & & 1.59 & $(1.28,1.99)$ & & \\
\hline Area smoking score & & & & & & & 1.46 & $(1.22,1.74)$ \\
\hline $\begin{array}{l}\text { Variance between } \\
\text { areas }(95 \% \mathrm{Cl})\end{array}$ & 0.023 & $(0.001,0.058)$ & 0.029 & $(0.002,0.074)$ & 0.023 & $(0.001,0.058)$ & 0.027 & $(0.002,0.066)$ \\
\hline $\mathrm{DIC}$ & 9088.5 & & 9096.9 & & 9094.7 & & 9093.5 & \\
\hline
\end{tabular}

a lower correlation with a person's social class than with the social class of their neighbours. Or it may be that the level of deprivation of the area of residence is a marker for risk accumulated throughout the lifecourse-the direct and indirect consequences of deprivation in earlier life as well as an accumulation of social circumstances. ${ }^{13} 31$

Although there is no dose-response relation between current smoking and the prevalence of CVD conditions, at an area level there is a positive correlation; people living in

\section{What this paper adds}

- Previous studies have shown the incidence and prevalence of cardiovascular disease to be linked to individual and area socioeconomic characteristics

- Cardiovascular disease in Scotland is more strongly patterned by area than by individual characteristics

- Aggregating individual social or behavioural risk factors to the area level strengthens the relation with individual cardiovascular disease prevalence areas in which more people smoke, and smoke more heavily, are more likely to have a CVD condition. This is another example where the aggregated characteristics of neighbours are more informative than those of the person. The reason for this is again likely to be the correlation between the individual measure and area deprivation; in deprived areas more people are likely to smoke and to smoke more heavily. So there may be a difference in meaning (and interpretation) between an individual measure and its aggregated counterpart.

The fact that the relation between the outcome and an aggregated (area level) variable may be stronger than that with the individual variable is worth further consideration for those involved in the analysis of survey data. Even in the

\section{Policy implications}

The strong association of poor health with area deprivation means that interventions may be more successful if their targets are based on area rather than individual characteristics 
absence of an external measure of deprivation-such as the Carstairs score as used in this paper-the aggregation of individual characteristics or risk factors may create important information about the context even with comparatively few observations per area.

Funding: the Social and Public Health Science Unit is jointly funded by the Medical Research Council and the Chief Scientist Office of the Scottish Executive Health Department.

Competing interests: none.

\section{REFERENCES}

1 Macintyre S, Maclver S, Sooman A. Area, class and health: should we be focusing on places or people? Journal of Social Policy 1993;22:213-34.

2 Sloggett A, Joshi H. Higher mortality in deprived areas: community or personal disadvantage? BMJ 1994;309:1470-4.

3 Morris RW, Whincup PH, Lampe FC, et al. Geographic variation in incidence of coronary heart disease in Britain: the contribution of established risk factors. Heart 2001;86:277-83.

4 Kölegård Stïärne M, Diderichsen F, Reuterwall C, et al. Socioeconomic context in area of living and risk of myocardial infarction: results from Stockholm heart epidemiology program (SHEEP). J Epidemiol Community Health 2002;56:29-35.

5 Borrell LN, Diez Roux AV, Rose K, et al. Neighbourhood characteristics and mortality in the atherosclerosis risk in communities study. Int I Epidemiol 2004;33:398-407.

6 Kölegård Stïärne M, Ponce de Leon A, Hallqvist J. Contextual effects of social fragmentation and material deprivation on risk of myocardial infarctionresults from the Stockholm heart epidemiology program (SHEEP). Int J Epidemiol 2004;33:732-41.

7 Franzini L, Spears W. Contributions of social context to inequalities in years of life lost to heart disease in Texas, USA. Soc Sci Med 2003:57:1847-61.

8 Steenland K, Henley J, Calle E, et al. Individual- and area-level socioeconomic status variables as predictors of mortality in a cohort of 179,383 persons. Am J Epidemiol 2004;159:1047-56.

9 Sundquist K, Malmström M, Johansson S-E. Neighbourhood deprivation and incidence of coronary heart disease: a multilevel study of 2.6 million women and men in Sweden. J Epidemiol Community Health 2004;58:71-7.

10 Emberson JR, Whincup PH, Morris RW, et al. Social class differences in coronary heart disease in middle-aged British men: implications for prevention. Int J Epidemiol 2004;33:289-96.

11 Lochner K, Kawachi I, Brennan RT, et al. Social capital and neighbourhood mortality rates in Chicago. Soc Sci Med 2003;56:1797-805.

12 Diez-Roux AV, Nieto FJ, Muntaner C, et al. Neighbourhood environments and coronary heart disease: a multilevel analysis. Am J Epidemiol 1997; 146:48-63.
13 Davey Smith G, Hart C, Watt G, et al. Individual social class, area-based deprivation, cardiovascular disease risk factors, and mortality: the Renfrew and Paisley study. J Epidemiol Community Health 1998;52:399-405.

14 Lawlor DA, Bedford C, Taylor M, et al. Geographical variation in cardiovascular disease, risk factors, and their control in older women: British women's heart and health study. J Epidemiol Community Health 2003;57:134-40.

15 Richards H, McConnachie A, Morrison C, et al. Social and gender variation in the prevalence, presentation and general practitioner provisional diagnosis of chest pain. J Epidemiol Community Health 2000;54:714-18.

16 Hart C, Ecob R, Davey Smith G. People, places and coronary heart disease risk factors: a multilevel analysis of the Scottish heart health study archive. Soc Sci Med 1997;45:893-902.

17 Diez Roux AV, Link BG, Northridge ME. A multilevel analysis of income inequality and cardiovascular disease risk factors. Soc Sci Med 2000;50:673-87.

18 Merlo J, Asplund K, Lynch J, et al. Population effects on individual systolic blood pressure: a multilevel analysis of the World Health Organisation MONICA project. Am J Epidemiol 2004;159:1168-79.

19 Sundquist J, Malmström M, Johansson S-E. Cardiovascular risk factors and the neighbourhood environment: a multilevel analysis. Int J Epidemiol 1999;28:841-5.

20 Blakely T, Hunt D, Woodward A. Confounding by socioeconomic position remains after adjusting for neighbourhood deprivation: an example using smoking and mortality. J Epidemiol Community Health 2004;58:1030-1.

21 Joint Health Surveys Unit of Social and Community Planning Research and University College London. Scottish health survey, 1998 [computer file]. Colchester, Essex: UK Data Archive, 2001

22 Shaw A, McMunn A, Field J. The Scottish health survey 1998. Edinburgh: Scottish Executive, 2000

23 Shaw A, McMunn A, Field J. The Scottish health survey 1998. Vol 2 Technical Report. Edinburgh: Scottish Executive, 2000.

24 Carstairs V, Morris R. Deprivation and health in Scotland. Aberdeen: Aberdeen University Press, 1991.

25 McLoone P, Boddy FA. Deprivation and mortality in Scotland, 1981 and 1991. BMJ 1994:309:1465-70.

26 Rasbash J, Browne W, Healy M, et al. MLwiN beta version 2.0. London: Centre for Multilevel Modelling, Institute of Education, 2003

27 Leyland AH, Goldstein H. Multilevel modelling of health statistics. Chichester: Wiley, 2001.

28 Spiegelhalter DJ, Nest NG, Carlin BP, et al. Bayesian measures of model complexity and fit. Journal of the Royal Statistical Society $B$ 2002;64:583-639.

29 Snijders TAB, Bosker RJ. Multilevel analysis. London: Sage, 1999.

30 Larsen K, Merlo J. Appropriate assessment of neighbourhood effects on individual health: integrating random and fixed effects in multilevel logistic regression. Am J Epidemiol 2005;161:81-8.

31 Davey Smith G, Hart C, Blane D, et al. Lifetime socio-economic position and mortality: prospective observational study. BMJ 1997;314:547-52. 